\title{
Beethoven en la cultura popular: de los Beatles a Tin Tán
}

Montserrat Pérez Lima

Conservatorio Nacional de Música

Las obras de arte no se hacen. Las obras de arte ocurren. El espacio que las podría acoger es aquel, imaginario, que recortan en torno a sí los objetos de deseo en el rito de su cortejo a su propio mundo. La liturgia de ese rito es aquello que el término especutacularidad encierra y transmite. Recogerlo es la única actitud, probablemente de devolver la música de nuestro tiempo al tiempo que es nuestro. Alessandro Baricco

Ludwig van Beethoven es una figura de la que no podemos escapar. Esta es una afirmación que el musicólogo Nicholas Cook sentenciaba para remarcar que el compositor había marcado un antes y después para el desarrollo de la música. Ludwig van Beethoven nos acompaña en la vida académica como parte del canon musical occidental, en efecto, es ineludible. Sin embargo, su presencia trasciende las salas de concierto, se vuelve parte de nuestra vida cotidiana. Nos aproximamos al personaje y su música en formas diversas, desde películas, cómics, videojuegos, incluso en protestas, comerciales y memes de Internet. Este es un ejercicio reflexivo en torno a la apropiación de la figura de Beethoven en la sociedad. Se realiza una vuelta a Beethoven a través de los ojos de Theodor Adorno y Walter Benjamin, a través de su reproducibilidad en las industrias culturales por los medios de comunicación y la cultura popular de los siglos XX y XXI.

Beethoven se convirtió en parteaguas para la creación de la figura del "artista".
Se dice que fue el primer músico independiente, que no trabajó para corte alguna o mecenas, que su trabajo fue resultado de sus necesidades creativas. Esto es en parte medio cierto, aunque si bien las figuras aristocráticas cambiaron por la burguesía, pero el compositor trabajó para ambos bandos. Algo que no se puede negar, es la naturaleza de la música del compositor, tal como lo señala el musicólogo Nicholas Cook ésta se encontraba "en [...] constante subversión de las expectativas convencionales, en [...] la lucha por conseguir un efecto heroico o una intimidad apasionada, en el modo en que era percibida, como si [le] hablara directamente a cada oyente como individuo" (Cook, 2006, p.36). La música de Beethoven dejó absortos a quienes habían conocido a sus antecesores, Mozart y Haydn. El compositor llevó al éxtasis a algunos, al mismo tiempo que creaba conflicto entre otros: "algunos oyentes de Beethoven siguieron sacando [la] idéntica conclusión [...]: que estaban escuchando la música de un loco o, como poco, la de un gran compositor cuya lamentable sordera había distorsionado su imaginación musical y, quizá, desequilibrado su mente" (Cook, 2006, p. 38). La "locura", la soledad y, ¡claro!, la sordera, se convirtieron en hitos que hoy acompañan la figura del compositor. Esta afirmación queda confirmada cuando uno se acerca a cualquier navegador de Internet y se aproxima a lo más buscado de Beethoven en la red. La gente busca al compositor porque lo conoce, algo sabe de él, quizá que era sordo, 
quizá que compuso la Quinta Sinfonía o el "Claro de luna".

Beethoven dejó marca desde su tiempo, con buenas o malas reseñas, pero se hablaba de él. Su música recorrió todo salón decimonónico donde hubiera un piano. Tuvo sus propios hits y grandes seguidores, muchos intelectuales, escritores y otros músicos, mismos que se reunieron a despedirlo aquel 29 de marzo de 1827 . Tras la muerte del maestro las calles de Viena se atiborraron de personajes como Hummel, Czerny, Krautzer, y por supuesto Schubert, entre otras veinte mil personas que asistieron al cortejo fúnebre. El violinista Yehudi Menuin y Curtis W. Davis en La música del hombre, nos describen cómo "Los ricos observaban desde sus carruajes, el pueblo curioseaba desde las ventanas o se disputaba el mejor lugar tras las vallas de contención" (Menuhin y Curtis, 1979, p.155). Esta escena nos da cuenta de la importancia que Beethoven tuvo en su sociedad, sin importar el rango social de la misma, su música había alcanzado a cada uno de ellos. Así como lo hizo con nosotros, más de doscientos años después.

Esta misma escena la vemos hoy en día una y otra vez con la partida de algún personaje de la música popular, ahora sabemos que no había sido la primera vez. Algo que también sabemos es que, al viajar a través del tiempo, Beethoven ha sobrevivido a guerras, revoluciones, vanguardias, innovaciones tecnológicas, incluso ha viajado al espacio: el primer movimiento de su Quinta sinfonía y la Cavatina del Cuarteto de cuerdas número trece en Si bemol mayor, Opus 130 se encuentran en el disco de oro de la sonda espacial Voyager junto con Bach, Stravinksy, sonidos de aves, autos, bebés, risas, saludos en 56 idiomas y latidos de un corazón que se convierte en el pulso de todo el planeta Tierra.
Esta ecléctica mezcla de sonidos e imágenes de la vida terrestre ilustra al mismo tiempo la situación donde está inmersa la figura de Beethoven, su relevancia actual, pero también nos deja ver que no ha escapado a la reproducibilidad. Porque, en efecto, no ha podido esquivar la reproducción masiva de nuestro tiempo. El carácter auténtico e irrepetible de su obra, el aura referida por Walter Benjamin, se ha visto trastocada por la oferta y demanda del mercado. Se trata de una situación que no se puede negar, pero que tampoco puede rechazarse sin hacer algunas consideraciones al respecto. Beethoven existe en un estado intermedio donde su aura permanece en el tiempo, pero, de igual forma, con ciertas mutaciones. Benjamin hablaba de cómo la obra poseía una "lejana unicidad", casi religiosa, de culto, lejana de ser reproducida por la sacudida de su aparición, única, original, comprendida por unos pocos, quizá sólo por uno, el creador y cómo, parte de la decadencia del aura, está relacionada con la imperiosa necesidad de las masas "de apoderarse del objeto todo lo cerca [posible], a través de su [...] imagen reproducida" (Benjamin, 2010, p. 19).

Regresando al ejemplo del disco de la sonda Voyager, es una reproducción de una grabación, no es siquiera una interpretación en vivo y, sin embargo, viaja en el espacio como una "digna" representación de la humanidad. Viene una segunda cara de la moneda de la reproductibilidad, también señalada por Benjamin: primero, "la reproducción técnica puede poner la copia en situaciones a las que no podría llegar el original" (Benjamin, 2010,p. 15) y segundo; la preponderancia del valor expositivo [que confiere] a la obra [...] [nuevas] funciones (Benjamin, 2010, p. 25). Si bien, una grabación sonora "devalúa" el aquí y ahora de una interpretación en vivo, esta se guarda para la posteridad 
y puede ser escuchada tiempo después, ya no sólo en la sala de conciertos, también en el auto, en el celular. Ahora cada quien ha desarrollado un propio ritual alrededor de la escucha de Beethoven y su música, si bien se corren ciertos riesgos para su apreciación profunda, sabemos que sigue en los oídos del mundo y que ha generado nuevos rituales, nuevas prácticas a partir de su resignificación.

Las grabaciones, pero también las señales de radio, televisión y cine han tenido gran impacto y una estrecha relación con la música del compositor. Al mismo tiempo, han ilustrado los escabrosos ejemplos de los que hablaban Theodor Adorno y Max Horkheimer (1988) al hacer referencia a la industria cultural. La música pasó a ser un recurso decorativo: como fondo musical de radionovelas, comedias o películas, incluso comerciales, perdiendo - ahí sí- su aura, pues no sólo era extraída del lugar de escucha contemplativa, sino que ni siquiera se daba pie al escucha para hacerlo, convirtiendo una totalidad orgánica - llámese sinfonía, sonata, cuarteto - en pequeños "leitmotiv" que permitieron prescindir de esa totalidad y halagar la vanidad del "pseudoculto" (Rodríguez, 2010 , p. 98). De esta forma nos quedamos con muy pocas piezas en la mente: el famoso "Claro de luna", el "Himno a la alegría", o con la impresión caricaturizada del "genio incomprendido" que era Beethoven. Con suerte algunas de esas personas conocerán más repertorio $\mathrm{y}$, con menor posibilidad quizá, algunos pocos lo comprenden como un discurso alejado de su breve aparición en la pantalla o en el programa de radio pues, como señalara Benjamin "aunque se pretendiera mostrar [las obras] a las masas [en los medios o, incluso], los museos y exposiciones, [estas] no podrían por sí mismas organizarse y controlar su disfrute" (Benjamín, 2010, p. 44). Ese temor o más bien advertencia de Adorno y Horkheimer sobre la decadencia de las masas parece seguir vigente, no logramos escapar de ese peligroso desliz.
La asociación entre la obra y su función ritual son centrales para la conservación del aura. Sin embargo, la "afectación" a la que son sometidas bajo la idea de la reproductividad ha resultado en ciertos "beneficios" con la llamada "democratización del arte", permitiendo el acceso a más personas que difícilmente podrían acercarse a las obras de otra manera. Si bien es cierto que se corre el riesgo de caer en una escucha superficial, también existen nuevas aproximaciones a la obra de Beethoven. Algunas de estas son realizadas con sumo cuidado y detalle, no sólo nos acercan al compositor, sino que, incluso nos adentran en su música, nos devuelven la capacidad de asombro y nos sitúan en un aquí y ahora. Benjamin señaló como "la masa es una matriz de la que resurgen, transformadas, todas las viejas actitudes ante la obra de arte" (Benjamin, 2010, p.52). Es a través de las interpretaciones reproducidas por las industrias culturales como mayormente conocemos a Beethoven, muy a pesar de que estén un poco diluidas o sean "ligeras". En este sentido, el cine ha brindado varios ejemplos donde el compositor y su obra han sido referenciados o utilizados de diversas maneras. Regresando al "Claro de Luna", es interesante su breve aparición en la película Misery (1990), donde tenemos una escena sumamente violenta, como contraste, la música. El primer movimiento de la sonata nos aleja del evidente sufrimiento físico, para colocarnos en el mundo interno del personaje, donde prima la desolación y la pérdida de la esperanza.

Vemos entonces que los productos creados por las industrias culturales para las "masas", tienen gran cantidad de matices en cuanto a su construcción y profundidad. Si bien Adorno señalaría como estas diferenciaciones corresponden a la creación y conservación de mercados específicos, lo cierto es que nos han dejado una enorme cantidad de ejemplos donde Beethoven ha participado. Su música ha aparecido en películas animadas y carica- 
turas como Fantasia (1940) de Disney o Charlie Brown. Su música ha sido el tema de series y programas televisivos, como el popular Chavo del ocho, cuya música inicial, The elephant never forgets de Jean-Jacques Perrey es en realidad parte del cuarto movimiento del opus 113, Las ruinas de Atenas. Y siguiendo en nuestro país, resulta interesante su aparición ya no como "fondo musical", sino como un ente todopoderoso en la película mexicana Locos Peligrosos (1957), donde Tin Tan y Luis Aguilar se disculpan ante el busto de Beethoven por verse seducidos por el ritmo del Cha cha chá.

Esta relación de adoración, temor y al mismo tiempo afrenta a la figura del compositor - a la música y la tradición que representa - es una que ha estado presente en la música popular. Tomemos el caso de los Beatles y su disco Roll over Beethoven (1964). Beatles y Beethoven aparecen juntos, si bien no en la música, si en el concepto: ambos se "anteponen", pero en realidad parecen estar más juntos que nada, pues lo que el rock and roll parecía confrontar a su tiempo, Beethoven lo fue para el suyo, rompiendo las reglas creadas por los grandes maestros que lo antecedieron.

Beethoven también ha aparecido en otros episodios de la historia. En este punto del relato vale la pena recordar una de las preocupaciones de Benjamin en torno a la reproducibilidad y la estetización de la vida política relacionada con el uso o creación de un valor cultual de la producción cultural en las masas. Este fue el caso de Hitler, particularmente de Goebbles quien vio en la música clásica alemana un estándar para promover el pensamiento nazi. La figura de Beethoven no escapó a esta asociación, su novena sinfonía fue ejecutada como parte de la celebración del cumpleaños de Hitler. Otro ejemplo donde la politización de su música se hizo evidente, ha sido como himno de protesta social. Tal es el caso de la versión del Himno a la alegría de Miguel Ríos (del cual seguramente Adorno hubiera pues- to un grito en el cielo) utilizado por las mujeres en lucha contra del régimen de Pinochet o en su ejecución en 1988 como parte de la celebración del derrumbe del Muro de Berlín. Esta "cercanía" con la obra, posiciona a Beethoven como un símbolo de algo que está por encima de la reproducción y, si bien, su cercanía puede no corresponder con una apreciación estética, tiene una relación más humana. Walter Benjamin "fue uno de los primeros en pensar que el ADN de una civilización se construye no solo con las curvas más altas de su pensar, sino también, [...] con sus movimientos en apariencia más insignificantes" (Baricco, 2006, p. 28). Si bien la figura de Beethoven en nuestra sociedad está envuelta de mitos y hechos anecdóticos que han sido aprovechados por diversas instancias, esto también ha servido para mantener una idea sobre la figura del 'artista' y del arte en general. Beethoven sigue en nuestra imaginación pues, como señala Alessandro Baricco, fue con él con quien "nació [...] la idea de música clásica que hemos heredado y de la que todavía nos servimos" (Baricco, 2006, p. 223). Apareció en los salones decimonónicos narrados por Tolstoi; como el repertorio favorito de Dorian Gray, nos hizo bailar en videojuegos como el Pum It Up, y, a veces, nos hace reír en memes de Facebook. Surge una disyuntiva alrededor de la figura de Beethoven, por un lado, sabemos "mucho" porque su figura no ha dejado de ser reproducida, pero, por otro, dudamos de la calidad de esas reproducciones, pues a veces ni siquiera se toman la molestia de advertirnos el origen o el por qué de la música, pasando a formar una parte más de nuestros consumos mediáticos. Sin darnos cuenta, a veces actuamos como unos "barbaros", atentamos contra una tradición de años atrás, pero al mismo tiempo entramos en conflicto porque aquella tradición no parece responder mucho a nuestra vida actual. Estas contradicciones ponen en la mesa la necesidad de repensar el impacto de los productos de la industria cultural, más 
allá del consumo inmediato, la necesidad de una reflexión o una aproximación a la obra desde distintos puntos de vista: académico, estético, histórico, sociocultural, etcétera. Como diría Baricco: "es necesario conceder a los bárbaros la oportunidad de ser un animal, con su plenitud, [...] y no [como] trozos de [un] cuerpo afectado por una enfermedad" (Baricco,
2006, p. 93). En este sentido, es necesario conceder el beneficio de la duda ante la mutación de nuestro vertiginoso mundo, aceptar las posibilidades de experiencias que nos ofrece, pero no estará de más estar preparados para confrontarlo o, en dado caso, disfrutarlo, recreando nuestro aquí y ahora.

FUENTES DE CONSULTA:

Baricco, Alessandro. (2006). Los Bárbaros. Ensayos sobre la mutación. Barcelona: Anagrama

Benjamin, Walter. (2010). La obra de arte en la época de su reproducción mecánica. España: Casimiro Cook, Nicholas. (2006). De Madonna al canto gregoriano. España: Alianza Editorial

Horkheimer, Max y Theodor Adorno. (1988). "La industria cultural. Iluminismo como mistificación de masas" en Dialéctica del iluminismo, Buenos Aires: Sudamericana

Menuhin, Yehudi y Curtis W. Davis. (1979). La música del hombre. Estados Unidos: Fondo Educativo Interamericano

Rodríguez-Ferrándiz, Raúl. (2010). «Música clásica y medios de comunicación: Roll over, Beethoven" en Revista Trípodos. número 26. ISSN 1138-3305, pp. 95-105 